\title{
A case of Jatropha multifida poisoning
}

\author{
K Guruge $^{1}$, A M R D Seneviratne ${ }^{2}$, C Badureliya ${ }^{3}$
}

Sri Lanka Journal of Child Health 2007; 36: 148

(Key words: Jatropha multifida poisoning, child)

On 16/07/2007 at 8.30 a.m. a $31 / 2$ year old girl from Kaduwela was found by her mother to be ingesting the seed of the Kapum Kiriya (Jatropha multifida) plant which was growing near the fence. The mother immediately removed the remaining particles of the seed from the child's mouth. The child spontaneously vomited several times and became drowsy. The parents brought the child to the Lady Ridgeway hospital by about 11.00 a.m. On admission, the child was drowsy and dehydrated. Gastric lavage was given, activated charcoal administered and intravenous fluid therapy started. The child recovered uneventfully and was discharged from the ward after 24 hours. Management was facilitated as the mother brought the flower with a part of the plant.

Jatropha multifida is a large shrub with distinctive large dark green leaves cut deeply into 7-11 narrow lobes, margins of each lobe being dissected into narrow pointed segments ${ }^{1}$. Flowers are bright coral red, borne in flattopped clusters on long stalks held high above the foliage ${ }^{1}$ (Figure 1). Fruits 3 lobed, $2.5 \mathrm{~cm}$ long, smooth and yellowish (Figure 2). The toxic element is a toxalbumin named jatrophin which causes agglutination and haemolysis of red cells and is also injurious to other cells ${ }^{1}$.

\section{${ }^{1}$ Consultant Paediatrician, ${ }^{2}$ Paediatric Registrar, ${ }^{3}$ House Officer, Lady Ridgeway Hospital, Colombo.}

(Received on 12 October 2007. Accepted on 26 October 2007)

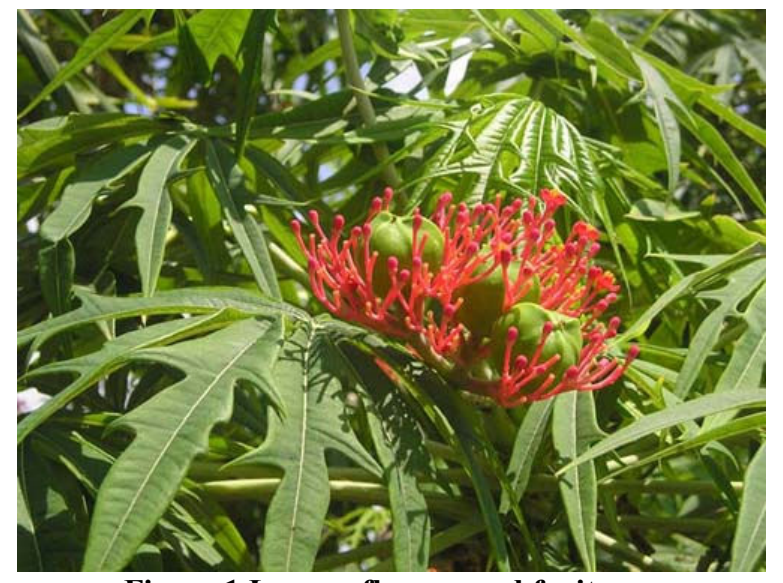

Figure 1 Leaves, flowers and fruits

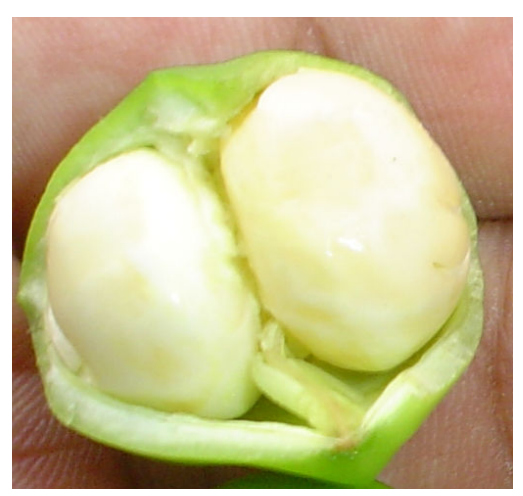

Figure 2 Fruit

\section{Reference}

1. Lucas G N, De Silva T U N. Poisonous Plants of Sri Lanka. $1^{\text {st }}$ ed. Colombo. Sri Lanka College of Paediatricians 2006. p25 